\title{
Calcineurin-dependent growth of an FK506- and CsA-hypersensitive mutant of Saccharomyces cerevisiae
}

\author{
Stephen A. Parent, Jennifer B. Nielsen, Nancy Morin, Gary Chrebet, NaAsa Ramadan, \\ Arlene M. Dahl, Ming-Jo Hsu, Keith A. Bostian† and Forrest Foor* \\ Microbiol Chemotherapeutics and Molecular Genetics (mail code R80Y-235), Merck Research Laboratories, Rahway, \\ NJ 07065, USA
}

(Received 29 April 1993; revised 14 July 1993; accepted 26 July 1993)

\begin{abstract}
The immunosuppressants FK506 and cyclosporin A (CsA) bound to their receptors, FKBP12 or cyclophilin, inhibit the $\mathrm{Ca}^{2+}$ /calmodulin-dependent protein phosphatase, calcineurin, preventing $\mathrm{T}$ cell activation or, in yeast, recovery from $\alpha$-mating factor arrest. Vegetative growth of yeast does not require calcineurin, and in strains sensitive to FK506 or CsA, growth is inhibited by concentrations of drug much higher than those required to inhibit $T$ cell activation or recovery from mating factor arrest. We now describe the isolation of a mutant of Saccharomyces cerevisiae which is 100-1000-fold more sensitive to the growth inhibitory properties of these drugs. The mutation $(f k s 1)$ also confers a slow growth phenotype which is partially suppressed by exogenously added $\mathrm{Ca}^{2+}$ and exacerbated by EGTA. Simultaneous disruption of the two genes (CNA1 and $C N A 2)$ encoding the alternative forms of the catalytic A subunit of calcineurin, or of the gene ( $C N B 1)$ encoding the regulatory $B$ subunit, is lethal in an $f k s 1$ mutant. Disruption of the gene encoding FKBP12 (FKB1) or the major, cytosolic cyclophilin (CPHI) in fksl cells results in the loss of hypersensitivity to the relevant drug. Overexpression of $C N A 1$ or $C N A 2$, in conjunction with $C N B 1$, results in a significant decrease in hypersensitivity to FK506 and CsA. The results show that the hypersensitivity of the $f k s l$ mutant is due to the inhibition of calcineurin phosphatase activity by the receptor-drug complexes. The growth dependence of the mutant on the $\mathrm{Ca}^{2+} /$ calcineurin signal pathway provides an important tool for studying in yeast certain aspects of immune suppression by these drugs.
\end{abstract}

\section{Introduction}

FK506 and cyclosporin A (CsA) are potent immunosuppressants, which inhibit an intermediate $\mathrm{Ca}^{2+}$-dependent step in $\mathrm{T}$ cell activation, blocking interleukin-2 (IL-2) production (reviewed in Sigal \& Dumont, 1992; Schreiber, 1992). The macrolide FK 506 binds with high affinity to the members of a family of highly conserved and ubiquitous proteins referred to as FK506 binding proteins (FKBPs). CsA is a cyclic undecapeptide which binds to members of another family of highly conserved and ubiquitous proteins called cyclophilins. The complex of binding protein with drug, FKBP12-FK506 or

* Author for correspondence. Tel. +1908594 6791; fax +1908594 5468; e-mail Forrest_Foor@Merck.com.

$\dagger$ Present address: Microcide Pharmaceuticals, 4040 Campbell Avenue, Menlo Park, CA 94025, USA.

Abbreviations: CsA, cyclosporin A; FKBP, FK506 binding protein; IL-2, interleukin-2; NPD, nonparental ditype; PD, parental ditype; SC medium, synthetic complete medium; T, tetratype; YPAD, yeast extract/peptone/adenine/dextrose; YPAG, yeast extract/peptone/ adenine/glycerol; YPD, yeast extract/peptone/dextrose.
cyclophilin-CsA, binds and inhibits the $\mathrm{Ca}^{2+}$ - and calmodulin-dependent protein phosphatase, calcineurin, suggesting that inhibition of calcineurin might be the mechanism of immunosuppression (Liu et al., 1991a). Transient overexpression of calcineurin in activated Jurkat human T cell lines containing the IL-2 promoter linked to a reporter gene resulted in decreased sensitivity of IL-2 promoter activity to FK506 or CsA (O'Keefe et al., 1992; Clipstone \& Crabtree, 1992). These results indicate that calcineurin is a component of the $T$ cell receptor signal transduction pathway, and that the drugs act by causing a loss of calcineurin function.

FK506 and CsA are also antibiotics which inhibit the growth of certain strains of yeast and fungi. The antifungal properties of these drugs and the existence of FKBPs, cyclophilins, and calcineurins in yeast and fungi have prompted genetic examinations of the mode of action of the drugs in these organisms. CsA-resistant mutants of Saccharomyces cerevisiae and Neurospora crassa either lack cyclophilin, or contain an altered receptor which fails to bind $\mathrm{CsA}$, indicating that cyclophilin mediates CsA cytotoxicity in these organisms 
Table 1. S. cerevisiae strains

\begin{tabular}{|c|c|c|}
\hline Strain & Characteristics & Derivation \\
\hline YFK005 & 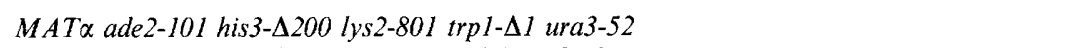 & Brizuela et al. (1991) \\
\hline YFK007 & MATa ade2-101 leu2- $\Delta 1$ lys2-801 trpI- $\Delta 1$ ura3-52 & Brizuela et al. (1991) \\
\hline YFK 132 & Same as YFK007 except fks $1-1 \mathrm{rho}^{-}$ & EMS mutagensis \\
\hline YFK 188 & Same as YFK007 except $f k b 1-2:: U R A 3$ & Transformation (Brizuela et al., 1991) \\
\hline YFK426-1A & 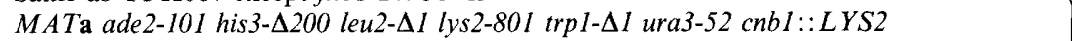 & \\
\hline YFK426-5A & 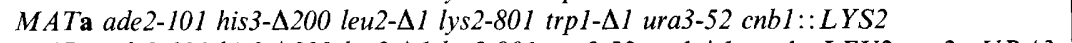 & \\
\hline YFK429-1D & 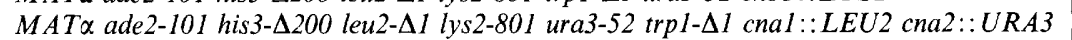 & Foor et al. (1992) \\
\hline YFK 429-3A & 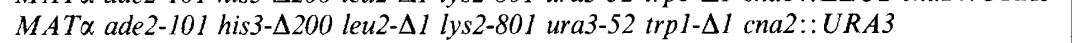 & \\
\hline YFK429-5A & 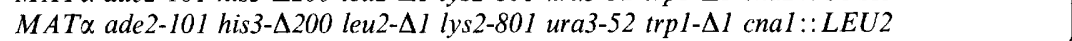 & \\
\hline YFK440 & YFK005 $\times$ YFK $132(F K S 1 / f k s l-1)$ & Mating \\
\hline YFK440-7D & 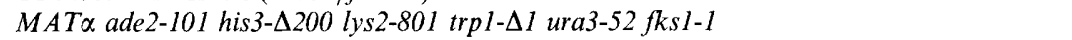 & Meiotic segregant \\
\hline YFK462 & YFK007 $\times$ YFK 440-7D $(F K S I / f k s 1-1)$ & Backcross \#1 \\
\hline YFK462-8C & 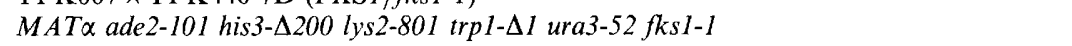 & Meiotic segregant \\
\hline YFK462-11A & $M A T \alpha$ ade $2-101$ his $3-\Delta 200$ lys $2-801$ trpl- -1 ura3-52 fksl-1 & Meiotic segregant \\
\hline YFK531 & YFK007 $\times$ YFK462-8C $(F K S 1 / f k s l-l)$ & Backcross \#2a \\
\hline YFK 531-5A & 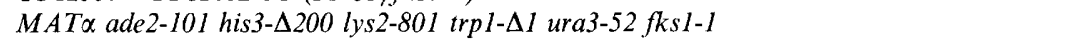 & Meiotic segregant \\
\hline YFK532 & YFK007 × YFK462-11A $(F K S 1 / f k s 1-1)$ & Backcross \#2b \\
\hline YFK532-2B & $M A T \alpha$ ade $2-101$ his $3-\Delta 200$ lys $2-801$ trp $1-\Delta 1$ ura3-52 fksl-1 & Meiotic segregant \\
\hline YFK 532-2D & 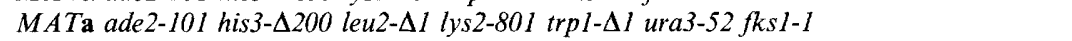 & Meiotic segregant \\
\hline YFK 532-5D & MATa ade2-101 leu2- $\Delta 1$ lys2-801 trpl- $\Delta 1$ ura3-52 fks -1 & Meiotic segregant \\
\hline YFK $532-7 \mathrm{C}$ & 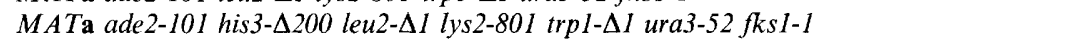 & Meiotic segregant \\
\hline YFK 532-10B & $M A T \mathbf{a}$ ade $2-101$ his $3-\Delta 200$ leu $2-\Delta 1$ lys $2-801$ trpl- $\Delta 1$ ura3-52 fks $1-1$ & Meiotic segregant \\
\hline YFK 547 & Same as YFK007 except $c p h 1:: A D E 2$ & Transformation (Foor et al., 1992) \\
\hline YFK 620 & YFK 532-2B $\times$ YFK 426-1A (CNB1/cnb1::LYS2 FKS1/fksl-1) & Mating \\
\hline YFK622 & YFK007 $\times$ YFK $532-2 \mathrm{~B}(F K S 1 / f k s l-1)$ & Backcross \# 3 \\
\hline YFK622-4D & 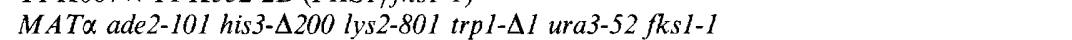 & Meiotic segregant \\
\hline YFK622-5D & MATa ade2-101 leu2- $\Delta 1$ lys2-801 trpl- $\Delta I$ ura3-52 fksl-1 & Meiotic segregant \\
\hline YFK628 & Same as YFK531-5A except $c p h 1:: A D E 2$ & Transformation \\
\hline YFK629 & Same as YFK 531-5A except $f k b 1-2:: U R A 3$ & Transformation \\
\hline YFK688 & YFK007 × YFK $622-4 D(F K S 1 / f k s l-l)$ & Backcross \# 4 \\
\hline YFK 768 & 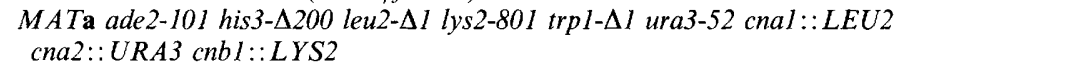 & (Foor et al., 1992) \\
\hline YFK801 & Same as YFK532-7C except $c p h 1:: A D E 2$ & Transformation \\
\hline YFK803 & Same as YFK 532-7C except $f k b l-2:: U R A 3$ & Transformation \\
\hline YFK 804 & Same as YFK 532-10B except cnal ::LEU2 & Transformation \\
\hline YFK805 & Same as YFK 532-10B except cna2::URA3 & Transformation \\
\hline YFK835 & MATa his4 leu2 lys 2 pep $4-3$ ura3-52 & CD24 from C. Douglas, Merck \\
\hline YFK 836 & Same as YFK007 except bar1::ADE2 & Transformation \\
\hline YFK837 & Same as YFK 132 except bar $1:: A D E 2$ & Transformation \\
\hline
\end{tabular}

(Tropschug et al., 1989). FK506-resistant mutants of $N$. crassa lack FKBP12 (Barthelmess \& Tropschug, 1993). However, similar experiments have not clearly delineated the role of an FKBP12-FK506 complex in mediating FK506 sensitivity in yeast. Disruption of the FKB1 gene encoding the yeast homologue of FKBP12 reduces sensitivity to FK506 only slightly (Brizuela $e t$ al., 1991; Heitman et al., 1991). It does, however, eliminate sensitivity to the FK506-related macrolide, rapamycin (Koltin et al., 1991; Brizuela et al., 1991). Rapamycin, which has been found to bind to most FKBPs, does not block IL-2 production, but inhibits later events required for full $\mathrm{T}$ cell activation. Consistent with this, the mammalian FKBP12-rapamycin complex does not bind or inhibit mammalian calcineurin (Liu et al., 1991a). Mutations in three yeast $F K R$ genes conferring FK506 resistance also have no effect on FKBP12 activity and map to loci distinct from FKB1 (Brizuela et al., 1991). Furthermore, the inhibition of yeast growth occurs at a concentration of FK506 more than 1000-fold higher than that which inhibits $\mathrm{T}$ cell activation. It is therefore likely that the mechanism of toxicity in wild-type yeast cells is unrelated to the mechanism of inhibition of $\mathrm{T}$ cell activation.

Calcineurin is a heterodimer consisting of one catalytic and one regulatory subunit. In yeast two genes (CNAI and $C N A 2$ ) encoding alternative catalytic subunits (A1 and $\mathrm{A} 2$ ), and one gene ( $C N B 1)$ encoding the regulatory $B$ subunit, have been described. Disruption of these genes has shown that calcineurin is not required for vegetative growth (Cyert et al., 1991; Cyert \& Thorner, 1992; Kuno et al., 1991; Liu et al., 1991 b; Nakamura et al., 1992). Thus, inhibition of calcineurin by FK506 or CsA would not explain the growth inhibitory properties of these drugs. However, yeast calcineurin has been implicated in recovery from $\alpha$-mating factor arrest: mutants lacking calcineurin fail to resume growth in the continued presence of $\alpha$-factor (Cyert et al., 1991; Cyert 
\& Thorner, 1992). In line with these observations, we found that recovery from mating factor arrest is highly sensitive to FK506 and CsA, at levels 100-1000-fold lower than those required to inhibit vegetative growth (Foor et al., 1992). Moreover, this sensitivity requires FKBP12 or cyclophilin, respectively. In addition, we were able to demonstrate that, just as for mammalian cells, FK 506 bound to yeast FKBP12 appears to form a complex with yeast calcineurin (Foor et al., 1992). Thus, the interactions of these receptor-drug complexes with calcineurin are highly conserved.

Here we describe the isolation and characterization of a mutation, $f k s l$, which renders the vegetative growth of yeast cells sensitive to levels of FK506 or CsA as low as those previously found to inhibit recovery from mating factor arrest. Hypersensitivity requires the presence of FKBP12 or cyclophilin. We surmised that, unlike wildtype strains, the mutant would require calcineurin for growth. Evidence is presented that this is indeed the case.

\section{Methods}

Yeast strains, media, and genetic methods. Yeast strains (Table 1) were grown at $28{ }^{\circ} \mathrm{C}$ (unless otherwise indicated) on synthetic complete medium (SC), yeast extract/peptone/dextrose (YPD), YPD supplemented with adenine (YPAD), or yeast extract/peptone/glycerol supplemented with adenine (YPAG) (Brizuela et al., 1991; Sherman et al., 1986). Supplements were added, when needed, after sterilization. Concentrated stock solutions of the antibiotics were prepared in methanol or ethanol. The amounts of solvent added to the media had no affect on growth. Standard methods were used for genetic analysis (Sherman et al., 1986) and DNA transformation (Becker \& Guarente, 1991). Tetrad dissections were performed on YPAD containing $10 \mathrm{~mm}-$ $\mathrm{CaCl}_{2}$. The construction and use of $f \mathrm{kbl}::$ URA3 (Brizuela et al., 1991), cphI::ADE2, cnal::LEU2, cna2::URA3 and cnb1::LYS2 (Foor et al., 1992) disruption fragments have been described. The bar $1:: A D E 2$ allele was constructed by synthesizing a $B A R I$ DNA fragment by polymerase chain reaction [residues 1 to 2729 of the sequence given by MacKay et al. (1988)] and replacing the $1.4 \mathrm{~kb} X b a \mathrm{I}-$ StuI fragment within the $B A R l$ gene with the $3.8 \mathrm{~kb} \mathrm{BamHI} A D E 2$ fragment from p669 (provided by P. Linder; Foor et al., 1992).

Growth inhibition assays. Sensitivity to $\alpha$-factor was determined by halo assay as described by Cyert $e$ t al. (1991). A replica plate assay was used to score the antibiotic sensitivities of various strains (Brizuela et al., 1991). Briefly, strains were patched onto solid YPAD medium lacking antibiotic, incubated for $2 \mathrm{~d}$ and then replicated onto solid medium with or without antibiotic, followed by growth for $1-2 \mathrm{~d}$. The lowest concentration of antibiotic preventing growth (minimum inhibitory concentration; MIC) was determined by inoculating a suspension of actively growing cells into medium containing serial dilutions of antibiotic. Tubes $(16 \mathrm{~mm})$ containing $1.0 \mathrm{ml}$ of medium were inoculated with ca. $2 \times 10^{4}$ cells for wild-type (YFK007) or $2 \times 10^{5}$ cells for $f k s I$ strains and incubated with shaking until growth of a control culture without antibiotic reached an $\mathrm{OD}_{600}$ of 1.0-1.6.

Isolation of mutants hypersensitive to FK506 and CsA. YFK005 and YFK007 were mutagenized with EMS by standard procedures (Sherman et al., 1986), plated on YPAD, and grown at $25^{\circ} \mathrm{C}$ for $5 \mathrm{~d}$. Colonies were replicated onto SC containing 0,1 , or $10 \mu \mathrm{g} \mathrm{FK} 506 \mathrm{ml}^{-1}$ and the replicates were incubated $1-2 \mathrm{~d}$ at $30^{\circ} \mathrm{C}$. Putative hyper- sensitive mutants were reisolated from the plates lacking FK506 and retested before further analysis. All mutants grew poorly on SC compared to the parent. Their growth and sensitivity to FK506 were greater on YPAD, making this the preferred medium for scoring the hypersensitive phenotype.

Construction of plasmids carrying the CNA1, CNA2 and CNBI genes. Individual phage clones containing the calcineurin genes were identified from a yeast genomic DNA library of strain S288C in $\lambda$-DASH (Stratagene, cat. no. 943901) by hybridization to probes synthesized from yeast genomic DNA by PCR (Foor et al., 1992). The CNA1, $C N A 2$ and $C N B I$ genes were mapped to $4.3 \mathrm{~kb} H i n d I I I, 4.3 \mathrm{~kb} B g l \mathrm{II}$ and $1.3 \mathrm{~kb} E c o$ RV DNA fragments within isolated phage clones, respectively. The $C N B I$ fragment was inserted into the $S m a$ I site of pBluescript II $\mathrm{KS}(+)$ in the lac $Z$ orientation and transferred as a BamHI-Eco RI fragment to the TRPI-selectable, single-copy and multicopy yeast shuttle vectors YCplac22 and YEplacl12 (Gietz \& Sugino, 1988), giving plasmids YCp-B and YEp-B, respectively. The CNAI fragment was inserted into the HindIII site and the CNA2 fragment into the BamHI site of YEp-B, giving YEp-A1-B and YEp-A2-B, respectively.

Purification of proteins. Recombinant yeast FKBP12 was purified from Escherichia coli (Nielsen et al., 1992). Yeast calmodulin was purified using an unpublished procedure (M. H. Pausch \& J. Thorner, University of California, Berkeley; personal communication) from a protease deficient strain (YFK835) containing plasmid pEL1 in which the yeast $C M D 1$ gene is expressed from the $G A L 1$ promoter (Davis \& Thorner, 1989). Yeast calcineurins were purified from strain YFK768 (cnal cna 2 cnbl) containing either YEp-A1-B or YEp-A2-B by DEAEcellulose chromatography followed by affinity chromatography on yeast calmodulin coupled to an agarose support essentially as described by Cyert \& Thorner (1992) except that the concentration of EGTA in the DEAE column buffer was increased from 1 to $3 \mathrm{~mm}$. The level of calcineurin during the purification was monitored by formation of the $100 \mathrm{kDa}$ complex of calcineurin with FKBP12-FK 506 as detected by Superose 12 chromatography with $\left[{ }^{3} \mathrm{H}\right]$ dihydro-FK 506 as described by Foor et al. (1992). Whole cell extracts were prepared as previously described (Foor et al., 1992; Nielsen et al., 1992). Samples of crude extracts contained $0.4 \mathrm{mg}$ of protein in $0.20 \mathrm{ml}$. Excess $\left[{ }^{3} \mathrm{H}\right]$ dihydroFK506 (104 nM), recombinant yeast FKBP12 $\left(1.2 \mu \mathrm{g} \mathrm{ml}^{-1}\right)$ and native yeast calmodulin $\left(0.7 \mu \mathrm{g} \mathrm{m}^{-1}\right)$ were added to the samples before loading. Under these conditions, all of the calcineurin is present in the complex (J. Nielsen \& M.-J. Hsu, unpublished observations). The formation of the complex is thus an accurate measure of the amount of calcineurin present in a sample. Calcineurin phosphatase activity was assayed as described by Liu et al. (1991a). The substrate was a synthetic peptide corresponding to the phosphorylation site of the RII subunit of cAMP-dependent protein kinase, which was phosphorylated with $\left[\gamma-{ }^{33} \mathrm{P}\right] \mathrm{ATP}$ at the serine residue. Reactions were started by the addition of $1 \mu \mathrm{M}$ substrate and incubated at $30^{\circ} \mathrm{C}$ for $10 \mathrm{~min}$. Less than $10 \%$ of the substrate was utilized in all cases. Values from reactions lacking enzyme were subtracted from those obtained with enzyme. Protein was measured with the Bio-Rad Protein Assay with bovine serum albumin as the standard.

\section{Results}

\section{Isolation of FK506-hypersensitive mutants}

Although inhibition of recovery from mating factor arrest in yeast is a good model for the inhibition of $T$ cell activation by FK506 (Foor et al., 1992), it is difficult to quantify the effects of the drugs or to select mutants experimentally. For this reason, we decided to investigate 
Table 2. Effect of $\mathrm{Ca}^{2+}$ on drug sensitivities of the fks I mutant

The wild-type (WT) strain (YFK007) and the $f k s I$ strain (YFK532-7C) were grown in YPAD with or without $10 \mathrm{mM}-\mathrm{CaCl}_{2}$. Antibiotic modes of action: amphotericin B (membrane integrity); anisomycin (protein synthesis); cycloheximide (protein synthesis); 5-fluorocytosine (DNA synthesis); ketoconazole (sterol synthesis); rapamycin (unknown); trifluoperazine . $2 \mathrm{HCl}$ (calmodulin antagonist). The results for FK506 and CsA were determined with twofold dilutions of drug; trifluoperazine with $5 \mu \mathrm{g} \mathrm{ml}^{-1}$ increments; and the other drugs with threefold dilutions.

\begin{tabular}{|c|c|c|c|c|c|c|c|c|c|c|}
\hline \multirow[b]{2}{*}{ Strain } & \multirow[b]{2}{*}{$\mathrm{Ca}^{2+}$} & \multicolumn{9}{|c|}{$\operatorname{MIC}\left(\mu \mathrm{g} \mathrm{ml}^{-1}\right)$} \\
\hline & & FK506 & $\mathrm{CsA}$ & $\begin{array}{l}\text { Ampho- } \\
\text { tericin B }\end{array}$ & $\begin{array}{l}\text { Aniso- } \\
\text { mycin }\end{array}$ & $\begin{array}{c}\text { Cyclo- } \\
\text { heximide }\end{array}$ & $\begin{array}{l}\text { 5-Fluoro- } \\
\text { cytosine }\end{array}$ & $\begin{array}{l}\text { Ketocon- } \\
\text { azole }\end{array}$ & $\begin{array}{l}\text { Rapa- } \\
\text { mycin }\end{array}$ & $\begin{array}{l}\text { Trifluo- } \\
\text { perazine }\end{array}$ \\
\hline WT & - & 50 & $>100$ & 0.5 & 20 & 0.03 & 10 & 1 & 0.003 & 15 \\
\hline WT & + & 50 & $>100$ & 0.5 & 20 & 0.03 & 10 & 1 & 0.003 & 20 \\
\hline$f k s l$ & - & 0.03 & 2 & 0.2 & 20 & $0 \cdot 03$ & 10 & 1 & 0.003 & 15 \\
\hline$f k s I$ & + & 0.03 & 4 & 0.5 & 20 & 0.03 & 10 & 1 & 0.003 & 15 \\
\hline
\end{tabular}

mutants of yeast hypersensitive to FK506 in the hope that hypersensitivity would prove to be more useful for investigating these interactions than recovery from mating factor arrest. The parental strains (YFK005 and

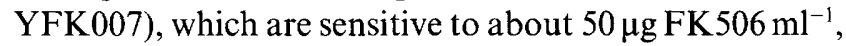
were mutagenized with EMS. We tested about 2100 isolates on drug plates containing 1 and $10 \mu \mathrm{g} \mathrm{FK} 506 \mathrm{ml}^{-1}$ and identified six hypersensitive mutants. One mutant (YFK132) was sensitive to $0 \cdot 1 \mu \mathrm{g} \mathrm{FK} 506 \mathrm{ml}^{-1}$. YFK132 was also sensitive to $10 \mu \mathrm{g} \mathrm{CsA} \mathrm{ml}^{-1}$, while its parent (YFK007) was insensitive to $100 \mu \mathrm{g} \mathrm{ml}^{-1}$. The mutant grew significantly more slowly than its parent, and also failed to grow on glycerol as a sole source of carbon.

\section{Genetic analysis of YFK132}

To determine whether the phenotypes of YFK132 were the result of a single mutation, tetrad analyses were performed on crosses between the mutant and wild-type strains. The FK506-hypersensitive and slow-growth phenotypes were recessive in all of the diploid isolates. All 15 tetrads with four viable spores from the cross of YFK132 with YFK005 yielded two FK506-hypersensitive and two nonhypersensitive spore colonies. FK506hypersensitive colonies were slow growing, while nonhypersensitive colonies grew normally. All segregants were capable of growth on glycerol, although we found that those which were hypersensitive to drug and slowgrowing produced daughter cells which failed to grow on glycerol at a higher frequency than the nonhypersensitive and fast growing segregants. Spore viability was low (ca. $72 \%$ ), probably due to additional EMS-induced mutations in YFK132. To improve spore viability, $M A T \alpha$ fksl meiotic segregants were repeatedly backcrossed to YFK007 to generate diploid YFK688 (Table 1). The viability of spores from this diploid was $88 \%$. All 24 tetrads with four viable spores from this diploid yielded two FK506-hypersensitive and two nonhypersensitive spore colonies. FK506-hypersensitive colonies were also sensitive to CsA and grew slowly, while the nonhypersensitive colonies were CsA resistant and grew normally. These results indicated that the drug-hypersensitive and slow-growth phenotypes of YFK132 resulted from mutation of a single nuclear gene, which we have called FKS1 (FK506 sensitive), while the failure to grow on glycerol was due to a cytoplasmic petite mutation.

\section{Effect of $\mathrm{Ca}^{2+}$ and drugs on the growth of the fksl mutant}

Further physiological examination of the $f k s l$ mutant revealed that its growth rate increases upon the addition of $\mathrm{CaCl}_{2}$ to the growth medium. For example, the doubling time of the $f k s 1$ strain YFK 532-7C decreased from $3.3 \mathrm{~h}$ in YPAD to $2.1 \mathrm{~h}$ in YPAD supplemented with $10 \mathrm{mM}-\mathrm{CaCl}_{2}$, the optimum level, while that of the wild-type strain (YFK007) increased slightly from 1.5 to $1.6 \mathrm{~h}$. Growth rates were not increased by higher concentrations of $\mathrm{NaCl}$ or $\mathrm{KCl}$, and only a slight effect was seen with $\mathrm{MgCl}_{2}$. Growth of the mutant was strongly inhibited by 4 mM-EGTA, a $\mathrm{Ca}^{2+}$ chelator, while that of the wild-type strain was unaffected. The addition of $\mathrm{CaCl}_{2}$ had no effect on sensitivity of the mutant to FK506 and resistance to CsA increased only slightly (Table 2). The mutant exhibited little or no difference from the wild-type strain in its sensitivity to a number of other antibiotics, in the presence or absence of $\mathrm{CaCl}_{2}$, including amphotericin $\mathrm{B}$, anisomycin, cycloheximide, 5-fluorocytosine, ketoconazole, lovastatin, and trifluoperazine (Table 2). These antibiotics are structurally and functionally distinct and have diverse modes of action. Thus, the hypersensitivity of the $f k s l$ mutant to the two immunosuppressants FK506 and CsA appears to be highly specific. 


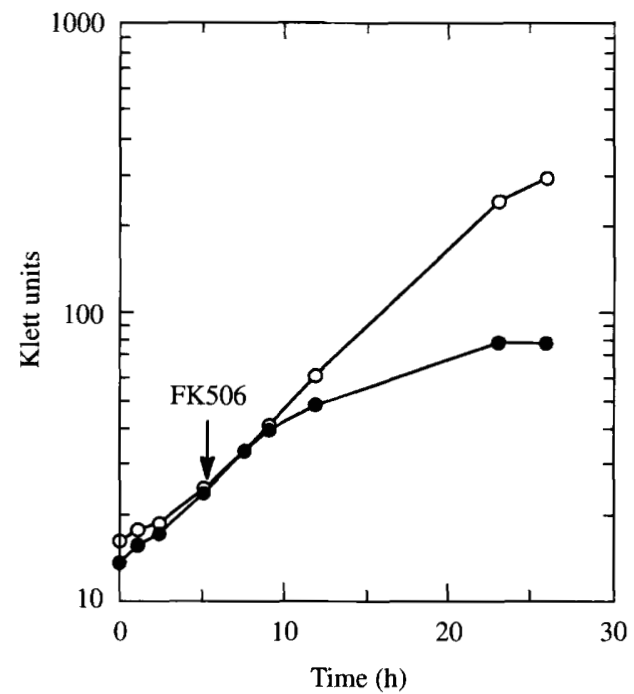

Fig. 1. Inhibition of growth of the $f k s I$ mutant by FK506. YFK132 $(f k s l)$ was grown in liquid YPAD medium. Growth was monitored in a Klett-Summerson colorimeter with a red (no. 66) filter. At the indicated time FK506 $\left(1 \mu \mathrm{g} \mathrm{m}^{-1}\right)$ was added to one of two cultures. $\mathrm{O}$, Culture without FK506; , culture with FK506.

Inhibition of growth by FK506 did not occur immediately upon addition of drug to an exponentiallygrowing culture. Rather, the growth rate decreased gradually over more than one generation, with the culture density increasing 3-3-fold before cessation of growth (Fig. 1). Drug-inhibited cells remained viable throughout the course of the experiment, even after growth had ceased (data not shown). Microscopic examination of the fully inhibited culture showed that the cells had stopped growing at all stages of the cell cycle as judged by the proportion of budded cells and the range of sizes of the buds (data not shown). No unusual morphological characteristics were observed.

\section{Requirement for FKBP12 or cyclophilin}

Disruption of $F K B 1$ in an $f k s I$ haploid strain resulted in loss of hypersensitivity to FK 506 (Fig. $2 a$ ), with no effect on hypersensitivity to CsA (Fig. $2 b$ ) or the slow growth phenotype. Conversely, disruption of $C P H I$ resulted in loss of hypersensitivity to CsA (Fig. 2b), with no effect on hypersensitivity to FK506 (Fig. 2a) or the slow growth phenotype. This indicated that each drug acts by binding to its specific cytosolic binding protein. In addition, since disruption of the gene encoding the binding protein for one drug did not alter hypersensitivity to the other drug or the slow growth phenotype, $f k s I$ cannot map to either $F K B 1$ or $C P H 1$. It was previously shown that disruption of $F K B 1$ results in resistance to rapamycin (Brizuela et al., 1991; Koltin et al., 1991). The same was true in the $f k s 1$ background (Fig. $2 c$ ). A genetic cross of an $f k s l$ haploid strain with
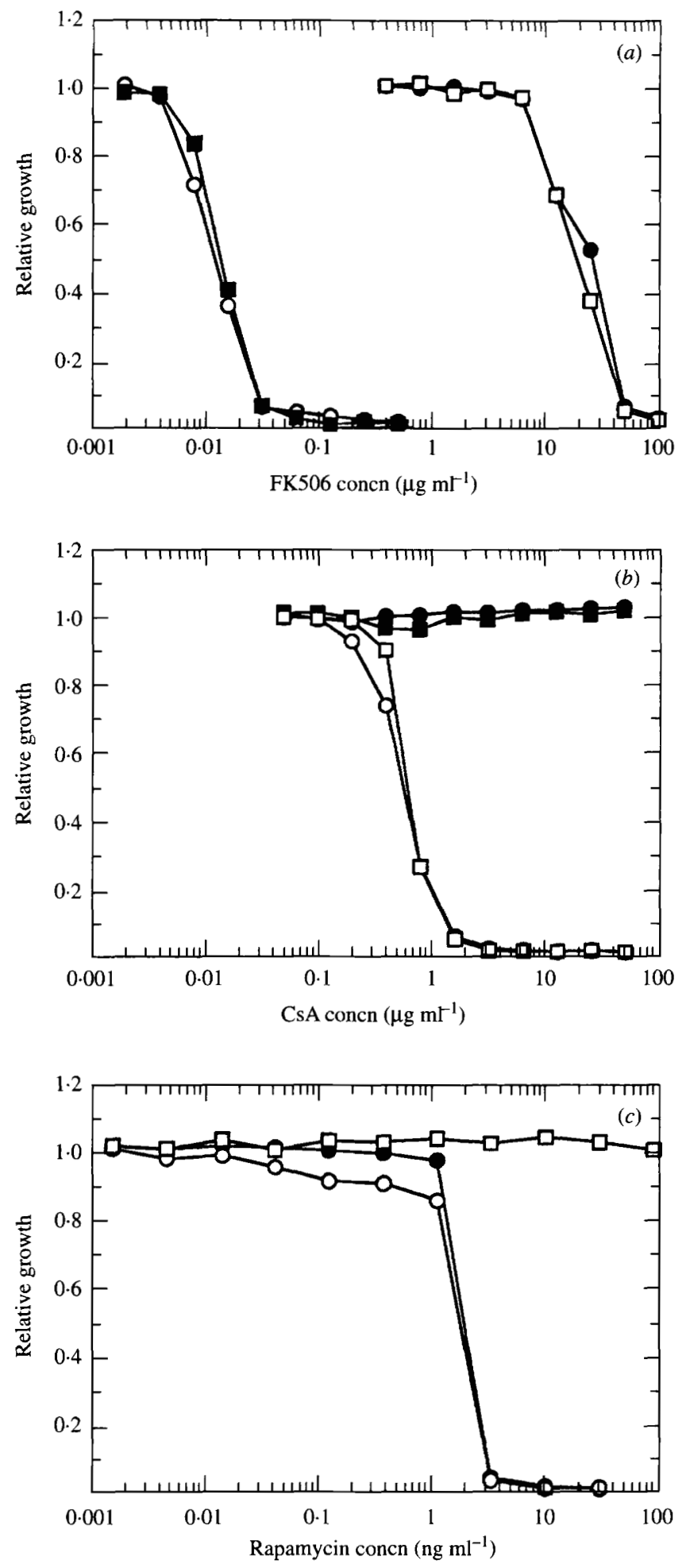

Fig. 2. Sensitivity of $f k s l$ cells to FK 506 and CsA is mediated by their respective binding proteins, FKBPl2 $(f k b l)$ and cyclophilin $(c p h l)$. YFK007 (wild-type) (O), YFK532-7C ( $k k s l)(O)$, YFK801 (fks I cphl) $(\square)$, and YFK803 ( $f k s l f k b l)(\square)$ were grown in liquid YPAD medium containing $10 \mathrm{~mm}-\mathrm{CaCl}_{2}$ in the presence or absence of $(a) \mathrm{FK} 506,(b)$ CsA, or $(c)$ rapamycin. Representative results from a single experiment are presented as the fraction of control growth in the absence of antibiotic. 


\section{Table 3. Genetic analysis of the fks1-1 mutation}

Diploids were created by crossing the indicated parents and sporulated, and tetrads were dissected. Adenine, leucine and lysine prototrophies were used as markers to follow the $c p h l$, $c n a l$, and $c n b l$ loci, respectively. Uracil prototrophy was used as marker to follow the $f k b I$ and cna2 loci. FK506 hypersensitivity was determined on YPAD supplemented with $1 \mu \mathrm{g}$ FK $506 \mathrm{ml}^{-1}$. CsA sensitivity was determined on YPD supplemented with $10 \mu \mathrm{g} \mathrm{CsA} \mathrm{ml}^{-1}$ for crosses YFK694 and YFK 700. Ascus types: PD, parental ditype; NPD, nonparental ditype; $\mathrm{T}$, tetratype. Ascus types were determined from 4-spore tetrads, and 3- and 2-spore tetrads when ascus types could be deduced.

\begin{tabular}{|c|c|c|c|c|c|c|}
\hline \multirow[b]{2}{*}{ Cross } & \multirow[b]{2}{*}{ Parents } & \multirow[b]{2}{*}{ Relevant genotype } & \multicolumn{3}{|c|}{ Ascus type } & \multirow{2}{*}{$\begin{array}{c}\text { Spore } \\
\text { viability } \\
(\%)\end{array}$} \\
\hline & & & $\mathrm{PD}$ & NPD & $\mathrm{T}$ & \\
\hline YFK 694 & YFK622-4D × YFK 188 & $f k s 1-1 \times f k b 1-2:: U R A 3$ & 3 & 3 & 9 & 85 \\
\hline YFK 700 & YFK622-4D × YFK 547 & $f k s 1-1 \times c p h l:: A D E 2$ & 3 & 3 & 9 & 88 \\
\hline YFK618 & YFK532-5D × YFK429-5A & $f k s 1-1 \times$ cnal $:: L E U 2$ & 27 & 4 & 42 & 81 \\
\hline YFK624 & YFK532-5D × YFK429-3A & $f k s 1-1 \times c n a 2:: U R A 3$ & 10 & 16 & 44 & 80 \\
\hline YFK620 & YFK 532-2B × YFK426-5A & $f k s 1-1 \times c n b 1:: L Y S 2$ & 11 & 9 & 45 & 66 \\
\hline
\end{tabular}

an $f k b 1:: U R A 3$ strain confirmed that $f k s l$ does not map to FKB1 (Table 3). The PD:NPD:T ratio was very close to the theoretical 1:1:4 expected for the random assortment of independent and unlinked genes. Parallel results were obtained in a cross of an $f k s I$ haploid strain with a cph1::ADE2 strain (Table 3).

\section{Growth of the fks 1 mutant is calcineurin-dependent}

Since FK506 and CsA, when bound to their receptors in extracts of mammalian cells, are inhibitors of calcineurin (Liu et al., 1991 a), we suspected that growth of the $f k s l$ mutant would be calcineurin-dependent. Haploid strains were transformed in separate experiments with purified DNA fragments carrying the cnal::LEU2, cna2::URA3, and cnb1::LYS2 alleles, and genomic DNA isolated from the transformants was analysed by Southern transfer hybridization. Those in which $C N A 1$ or $C N A 2$ was disrupted remained hypersensitive to FK506 with no change in the MIC (30 $\left.\mathrm{ng} \mathrm{ml}^{-1}\right)$. Disruptants of $C N A 2$, however, showed a pronounced decrease in growth rate on YPAD relative to the $f k s l$ parent (data not shown). The greater effect of cna2::URA3 compared to cnal::LEU2 on the growth of the $f k s 1$ mutant is similar to their effects on recovery from $\alpha$-factor arrest in the wild type (Foor et al., 1992). We were unable to disrupt $C N B 1$, or simultaneously the two $C N A$ genes, in the $f k s l$ mutant. These results were consistent with the idea that growth of the $f k s 1$ mutant is calcineurin-dependent.

To prove this, we crossed $f k s l$ strains with strains containing disruptions of the calcineurin genes. In the cross between $f k s 1$ and $c n b 1:: L Y S 2$ only a small fraction $(8 / 73)$ of the dissected tetrads had 4 viable spores, while a large proportion had three $(33 / 73)$ or two $(27 / 73)$ viable spores. All of the tetrads with four viable spores were parental ditype with two $f k s 1$ and two $c n b 1:: L Y S 2$ spores. Of the 33 tetrads with three viable spores, 30 were tetratype with wild-type, $f k s 1$, and $c n b 1:: L Y S 2$ viable spores and one inviable spore predicted to be $f k s I$ $c n b 1:: L Y S 2$; the remaining 3 were parental ditype with one $f k s 1$ and two cnb1::LYS2 viable spores and one inviable spore predicted to be $f k s l$. Of the 27 tetrads with two viable spores, 15 were tetratype with one wild-type and one $c n b 1:: L Y S 2$ viable spore. Of the remaining 12, nine were nonparental ditype with two wild-type viable spores and two inviable spores predicted to be $f k s l$ $c n b 1:: L Y S 2$, and 3 were of unknown type with one $f k s 1$ and one $c n b 1:: L Y S 2$ viable spore. Thus, none of 63 $f k s 1$ cnb1::LYS2 spores was viable, establishing that disruption of $C N B 1$ in the presence of the $f k s 1$ mutation is lethal to the spores. The number of tetrads of each type in this cross are listed in Table 3. The PD:NPD:T ratio is very close to $1: 1: 4$ consistent with $F K S 1$ and $C N B 1$ being independent and unlinked genes.

We also crossed $f k s 1$ strains with cnal::LEU2 or cna2::URA3 strains (Table 3). Spores with $f k s l$ and cnal::LEU2 alleles or $f k s 1$ and cna2::URA3 alleles were viable. The PD:NPD:T ratios indicated that the $f k s l$ mutation does not map to $C N A 1$ and $C N A 2$. The data suggest that cnal::LEU2 and $f k s l$ are linked at a distance of about $48 \mathrm{cM}$. When we crossed $f k s 1$ cna1::LEU2 and cna1::LEU2 cna2::URA3 strains, the results were qualitatively similar to those obtained in the cross with cnb1::LYS2. There was a significant drop in the level of spore viability, and none of 49 spores predicted from tetrad analysis to be $f k s 1$ cnal::LEU2 cna2::URA3 was viable (detailed data not presented). Thus, in an $f k s l$ mutant simultaneous disruption of the two genes encoding the alternative catalytic subunits of calcineurin or disruption of the single gene encoding the common regulatory subunit yielded inviable spores. These findings parallel the effects of calcineurin gene 

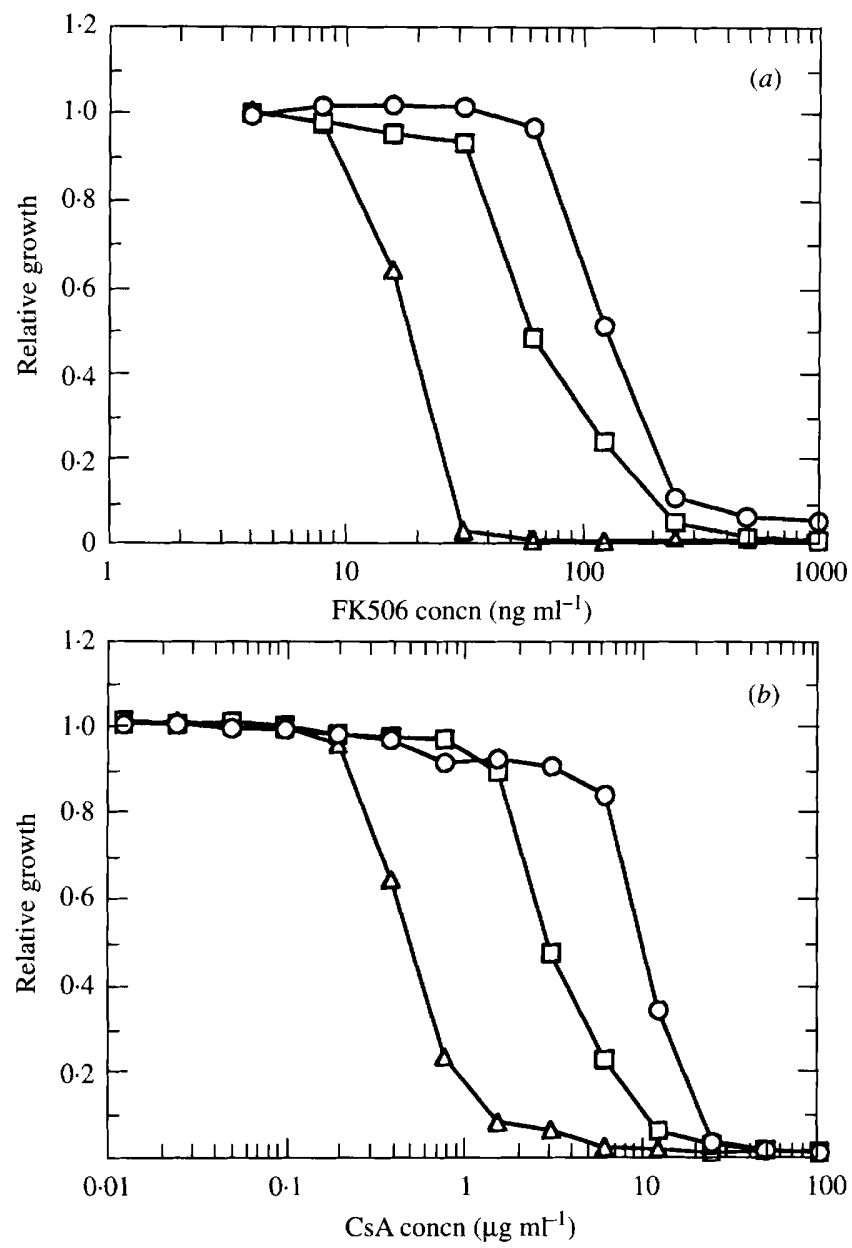

Fig. 3. Calcineurin overexpression in $f k s l$ cells confers FK 506 and CsA resistance. YFK531-5A ( $f k s l)$ transformants containing plasmid YEpAl-B $(\square)$, YEp-A2-B $(O)$, or YEplac112 (vector) $(\triangle)$ were grown in liquid YPAD medium containing $10 \mathrm{mM}-\mathrm{CaCl}_{2}$ (to ameliorate the slow-growth defect of the $f k s I$ strain) in the presence or absence of $(a)$ FK 506 or (b) CsA. Representative results from a single experiment are presented as the fraction of control growth in the absence of antibiotic. The experiment was repeated with essentially the same results.

disruptions on recovery from mating factor arrest (Cyert et al., 1991; Cyert \& Thorner, 1992; Foor et al., 1992) and are consistent with the idea that the two yeast calcineurins have redundant, or at least overlapping, functions.

To determine whether $f k s 1$ cnbl::LYS2 double mutants merely fail to germinate or are also unable to grow vegetatively, we transformed a plasmid carrying $C N B 1$ and TRP1 (YCp-B) into diploid YFK620 (FKS1/fks1 CNB1/cnb1::LYS2). In 57 tetrads from this strain, spore viability was ca. $72 \%$ and $18 f k s 1$ $c n b 1:: L Y S 2$ spores were recovered. All of the $f k s 1$ cnb1::LYS2 spores which grew also carried the CNB1 plasmid as judged by their $\operatorname{Trp}^{+}$phenotype. Thus, the $C N B 1$ gene on the plasmid complemented the defect of the $f k s 1$ cnb1::LYS2 mutant. We also grew independent $f k s 1$ and $f k s 1$ cnbl::LYS2 meiotic segregants containing the $C N B I$ plasmid for several generations nonselectively to allow plasmid loss, and then measured the fraction of cells which had retained or lost the plasmid. All of the colonies from the fks $1 \mathrm{cnb} 1:: L Y S 2$ haploids remained $\operatorname{Trp}^{+}$(ca. 900 were tested), whereas only a small fraction $(6 \%)$ of the $f k s l$ colonies remained $\operatorname{Trp}^{+}$(ca. 1700 were tested). The failure to lose the $C N B 1$ plasmid in fks1 cnb1::LYS2 double mutants demonstrated that vegetative growth of the $f k s l$ mutant is calcineurindependent.

\section{Expression of fks1-1 and mating type control}

Recovery from mating factor arrest is calcineurindependent and, as such, resembles the growth of the $f k s l$ mutant. It seemed possible that the mutant might be growing in a state similar to that seen during recovery from mating factor arrest, and that the $f k s l$ mutation might therefore be signalling the presence of $\alpha$-factor even in its absence. In this case one might expect the $f k s I$ mutant to be relatively resistant to the growth arrest induced by exposure of cells to $\alpha$-factor, since the cells would already be in a state of recovery. However, the mutant and the wild-type strains did not differ in their response to $\alpha$-factor (data not shown). To test this further, we disrupted $B A R 1$, the gene encoding $\alpha$-factor protease (MacKay et al., 1988). Mutations in this gene confer hypersensitivity to $\alpha$-factor. Strains YFK836 (barl) and YFK 837 (fksl barl) were both hypersensitive to $\alpha$-factor and did not differ from each other in their response to it.

It also seemed possible that the $f k s l$ phenotypes might be under mating type control and only be expressed in $M A T \mathbf{a}$ haploid cells. However, in the crosses described above, we found that the phenotypes were expressed equally well in $M A T \alpha$ segregants. Expression of the $f k s l$ phenotypes could also be under cell type control and not be expressed in homozygous $f k s I$ diploids. Four $M A T$ a $f k s l$ and four $M A T \alpha f k s l$ segregants were crossed generating $16 \mathrm{fks} 1$ homozygous diploids. All of these diploids were hypersensitive to FK506 and grew even more slowly than $f k s l$ haploids (data not shown). Thus, expression of the $f k s l$ phenotypes is not under mating type control.

\section{Overexpression of calcineurin}

Since growth of the $f k s l$ mutant is calcineurin-dependent, we postulated that hypersensitivity to FK506 and CsA was due to inhibition of this enzyme by the drugs. To test this in vivo, we overexpressed calcineurin. The presence of a multicopy plasmid carrying $C N A I$ and $C N B I$ (YEp$\mathrm{Al}$-B), or $C N A 2$ and $C N B 1$ (YEp-A2-B) in the $f k s l$ 


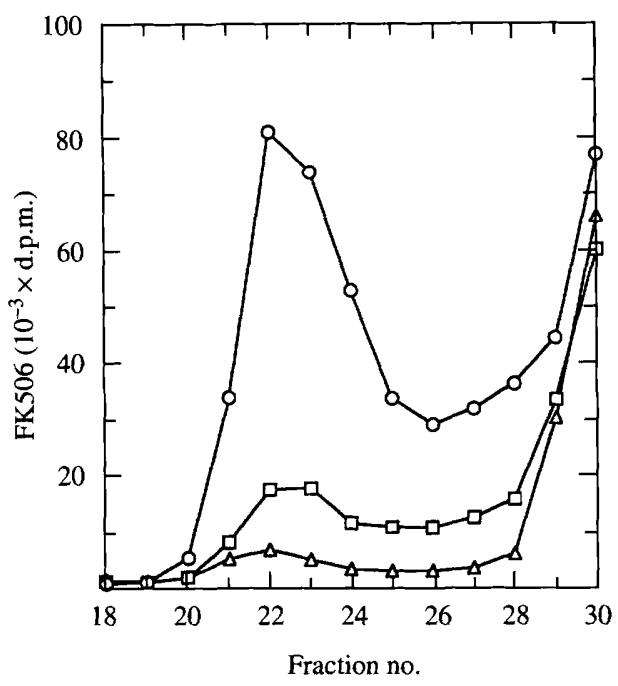

Fig. 4. Overexpression of calcineurin as measured by the formation of the $100 \mathrm{kDa}$ FKBP12-FK506 binding complex in extracts of $f k s l$ cells. See Methods for details of sample preparation and Superose 12 chromatography. YFK531-5A $(f k s 1)$ transformants containing plasmid YEp-A1-B $(\square)$, YEp-A2-B $(O)$, or YEplac112 (vector) $(\triangle)$ were grown in liquid YPAD medium containing $10 \mathrm{~mm}-\mathrm{CaCl}_{2}$. Plasmid loss was $47 \%, 37 \%$, and $20 \%$, respectively. Each column profile presents data from a single experiment. The experiment was repeated with independent transformants with essentially the same results.

mutant increased resistance to FK506 and CsA compared to a control strain with the vector alone (Fig. 3). These results parallel those seen in Jurkat $\mathrm{T}$ cell lines overexpressing calcineurin (O'Keefe et al., 1992; Clipstone \& Crabtree, 1992). Yeast cells with YEp-A2-B were significantly more resistant to both drugs than those with YEp-A1-B (Fig. 3). Moreover, the presence of YEp-A2$\mathrm{B}$ decreased the doubling time of the mutant in the absence of $\mathrm{Ca}^{2+}$ from 3.2 to $2.8 \mathrm{~h}$, and in the presence of $\mathrm{Ca}^{2+}$, from $2 \cdot 2$ to $2 \cdot 0 \mathrm{~h}$.

The level of overexpression of calcineurin in the $f k s l$ cells with the plasmids was quantified as follows. We previously demonstrated in crude yeast extracts that FK506 binds to yeast FKBP12 and forms a $100 \mathrm{kDa}$ complex with yeast calcineurin and calmodulin which can be detected by chromatography on Superose 12 (Foor et al., 1992). The formation of this complex was used to determine the levels of calcineurin in strains containing the multicopy calcineurin plasmids (Fig. 4). Maximum levels of the complex were obtained only when the extracts were supplemented with purified yeast FKBP12 and calmodulin, indicating that these components were limiting in extracts from strains in which calcineurin was overexpressed. Other experiments (data not shown) demonstrated that the presence of excess FK506, FKBP12 and calmodulin, causes the complete conversion of calcineurin to the complexed form and, under these conditions, the amount of complex is an accurate measure of the level of the enzyme in the sample. The $f k s 1$ strain with YEp-A1-B contained 3.7fold more calcineurin than the $f k s l$ strain with vector alone, while the $f k s 1$ strain with YEp-A2-B contained 14fold more. The ratio of the type 1 calcineurin (the form containing the Al catalytic subunit) to type 2 (containing the A2 subunit) is similar to that obtained in extracts of strains in which calcineurin is not overexpressed (Foor et al., 1992), and may simply reflect a difference in the promoter activities of $C N A 1$ and $C N A 2$.

The overexpression of each calcineurin in strains with the $F K S 1$ wild-type allele was also determined. YFK768 (cnal cna2 cnbl) was transformed with YEp-Al-B and YEp-A2-B, and the level of calcineurin was quantified as before. The strain with YEp-A1-B contained 18-fold more calcineurin than the wild-type strain YFK007, while that with YEp-A2-B contained 42-fold more. The high levels of calcineurin in the strain with YEp-A2-B allowed us to detect the presence of FKBP12 in the $100 \mathrm{kDa}$ complex by antibody staining (Fig. 5). Previously, the presence of FKBP12 in the complex was inferred from the failure of the complex to form in extracts of mutants lacking FKBP12 (Foor et al., 1992). In the absence of FK506 (Fig. 5, upper panel), FKBP12 eluted in fractions 34 and 35 . In the presence of FK506 (lower panel), most of the FKBP12 was found in fractions 22 to 25 , which contained the calcineurindependent $100 \mathrm{kDa}$ complex. A small amount of FKBP12 eluted in fraction 31. Control experiments with purified FKBP12 alone showed a similar change in the position of elution of FKBP12 upon the addition of drug, suggesting that drug binding induces a conformational change in the protein.

\section{Purification of the yeast calcineurins from overexpressing strains}

It has never been directly demonstrated that the enzymic activity of yeast calcineurin is inhibited by FKBP12FK506. The assay of the phosphatase activity of yeast calcineurin is extremely difficult in crude preparations due to the presence of other dephosphorylating enzymes. In order to test for inhibition and to further characterize the formation of the inhibitory complex, we purified the two types of calcineurin from extracts of the highproducing strains. The purification procedure consisted of DEAE-cellulose chromatography followed by affinity chromatography on immobilized yeast calmodulin. Both enzymes were nearly homogeneous as judged by silver staining of an SDS-polyacrylamide gel (data not shown). The formation of the $100 \mathrm{kDa}$ complex could also be demonstrated with these highly purified yeast calcineurins, and required the addition of FK506, FKBP12 and calmodulin. The requirement for calmodulin has also been shown previously with relatively crude yeast 


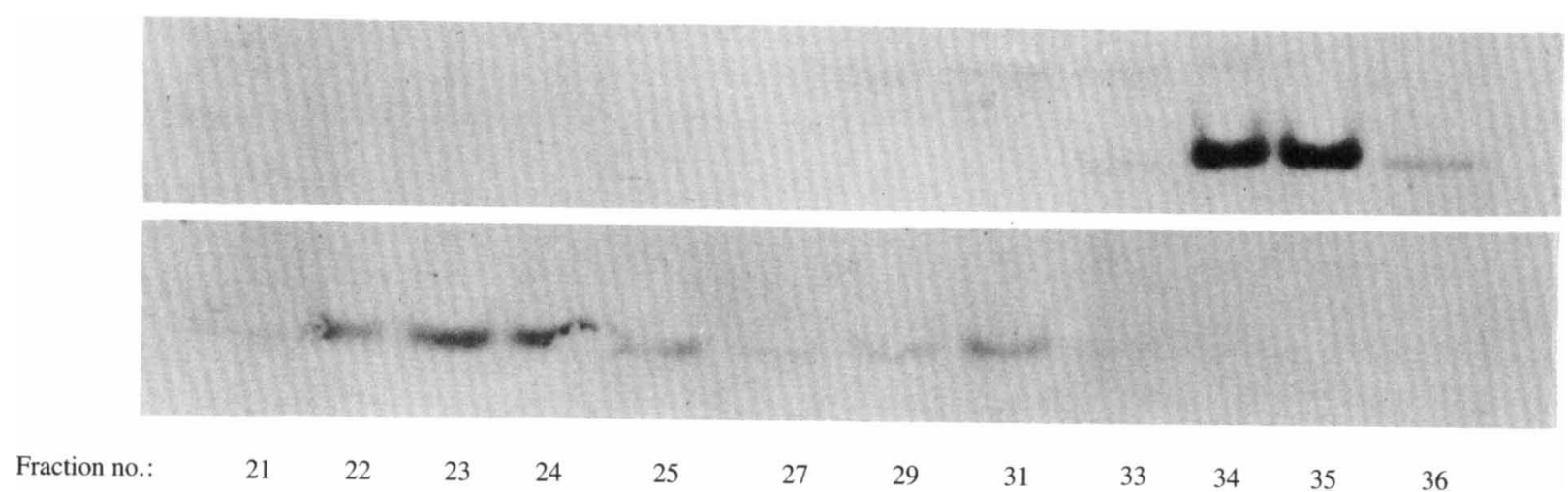

Fig. 5. Presence of FKBP12 in the $100 \mathrm{kDa}$ complex demonstrated by Western blot. Whole cell extract of YFK 768 containing plasmid YEp-A2-B was incubated in the absence (upper panel) or presence (lower panel) of FK506 and chromatographed on Superose 12 as described in Methods. Fractions from the column were concentrated by TCA precipitation and fractionated by electrophoresis in an SDS-polyacrylamide gel. FKBP12 was detected by Western blot analysis (Nielsen et al., 1991) with rabbit antiserum raised against yeast FKBP12.

Table 4. Inhibition of yeast calcineurin by FK506-FKBP12

Phosphatase assays were performed in duplicate with 20 nM-yeast calcineurin in the absence of $\mathrm{Mn}^{2+}$. The concentration of calcineurin was reduced to $1 \mathrm{nM}$ in the presence of $\mathrm{Mn}^{2+}$. Enzyme specific activity (SA) is reported as nmol phosphate released $\min ^{-1}$ (mg calcineurin) $)^{-1}$. Additions: $2 \mu \mathrm{M}$-yeast FKBP12, $1 \mu \mathrm{M}$-FK506, I $\mu \mathrm{M}$-rapamycin, $1 \mathrm{~mm}-\mathrm{MnCl}_{2}$ and $0.88 \mathrm{~mm}$ EGTA. Relative activities (RA) are reported separately for reactions with and without $\mathrm{Mn}^{2+}$.

\begin{tabular}{|c|c|c|c|c|}
\hline \multirow[b]{2}{*}{ Assay additions } & \multicolumn{2}{|c|}{ Type 1 calcineurin } & \multicolumn{2}{|c|}{ Type 2 calcineurin } \\
\hline & SA & RA & SA & RA \\
\hline None & $4 \cdot 75$ & $(1 \cdot 00)$ & $5 \cdot 38$ & $(1.00)$ \\
\hline FKBP12 & $4 \cdot 61$ & 0.97 & $5 \cdot 44$ & 1.01 \\
\hline FK506 & $4 \cdot 66$ & 0.98 & $5 \cdot 23$ & 0.97 \\
\hline FKBP12 + FK 506 & $0 \cdot 32$ & 0.07 & 0.62 & $0 \cdot 11$ \\
\hline FKBP12 + rapamycin & $5 \cdot 13$ & $1 \cdot 08$ & $5 \cdot 46$ & 1.02 \\
\hline $\mathrm{Mn}^{2+}$ & 104 & $(1 \cdot 00)$ & 116 & $(1 \cdot 00)$ \\
\hline $\mathrm{Mn}^{2+}+\mathrm{FKBP} 12$ & 99 & 0.95 & 118 & 1.02 \\
\hline $\mathrm{Mn}^{2+}+\mathrm{FK} 506$ & 101 & 0.97 & 110 & 0.95 \\
\hline $\mathrm{Mn}^{2+}+\mathrm{FKBP} 12+\mathrm{FK} 506$ & 9 & 0.09 & 15 & 0.13 \\
\hline $\mathrm{Mn}^{2+}+$ FKBP 12 + rapamycin & 99 & 0.95 & 113 & 0.98 \\
\hline EGTA $-\mathrm{Ca}^{2+}-$ calmodulin & $0 \cdot 13$ & - & $0 \cdot 15$ & - \\
\hline
\end{tabular}

preparations (Foor et al., 1992) and with mammalian proteins (Wiederrecht et al., 1992). The formation of the $100 \mathrm{kDa}$ complex with the type 1 calcineurin, but not type 2, was stimulated by $1 \mathrm{mM}-\mathrm{MnCl}_{2}$ added to the sample applied to the column (data not shown). This was only found with the enzyme preparation obtained after the calmodulin affinity chromatography step. $\mathrm{MnCl}_{2}$ had no effect with crude extracts or fractions obtained after chromatography on DEAE-cellulose. Mammalian calcineurin contains several species of multivalent cations, including $\mathrm{Zn}^{2+}, \mathrm{Fe}^{3+}$ and $\mathrm{Ca}^{2+}$ (Pallen et al., 1988). One or more of these may have been partially removed from the yeast protein, since the calmodulin affinity chromatography step was carried out in the presence of excess EGTA. Although $\mathrm{Mn}^{2+}$ may substitute for one of these, it is also possible that trace contamination of the $\mathrm{MnCl}_{2}$ solution with other multivalent cations is responsible for restoration of the ability of the type 1 calcineurin to form the complex with FKBP12-FK506.

\section{Inhibition of yeast calcineurin by FKBP12-FK506}

Purification of the calcineurins allowed us to test directly the inhibition of phosphatase activity by FKBP12FK506. It has been reported that after calmodulin affinity chromatography, calcineurin is converted to a form with low specific activity in the presence of $\mathrm{Ca}^{2+}$ and calmodulin. Reactivation can only be achieved by preincubation with $\mathrm{Mn}^{2+}(1.0 \mathrm{~mm})$ and not $\mathrm{Ca}^{2+}$ (Stewart et al., 1982). We found this to be true with both the type 1 and type 2 preparations (Table 4). However, as shown in Table 4, both the $\mathrm{Ca}^{2+}$ - and $\mathrm{Mn}^{2+}$-dependent activities 
are potently inhibited by the FKBP12-FK 506 complex. FKBP12-rapamycin did not significantly inhibit the phosphatase activity, consistent with previous observations that rapamycin inhibits a different, $\mathrm{Ca}^{2+}$-independent, signalling pathway (Sigal \& Dumont, 1992).

\section{Discussion}

The yeast $f k s 1$ mutant provides a model for the inhibition of calcineurin and therefore of $T$ cell activation by FK506 or CsA. The strain is sensitive to levels of these drugs approaching the nanomolar concentrations which inhibit $T$ cells. Inhibition requires the same drug receptors, FKBP12 and cyclophilin, and is mediated by the binding of the receptor-drug complexes to calcineurin and the inhibition of its enzymic activity. Inhibition of growth is a more useful phenotype for studying these interactions than is recovery from mating factor arrest.

Although other CsA-sensitive yeast mutants have been described (Tropschug et al., 1989; Koser et al., 1991), their sensitivity to FK506 was not reported. Tropschug et al. (1989) also noted an association of a petite phenotype with CsA-sensitive yeast mutants. Their results implied that a petite phenotype was necessary for CsA sensitivity. Our results show that this is not necessarily the case, but that CsA-sensitive strains segregate petites at a high frequency. However, the relationship of their mutations to the $f k s I$ allele is unknown.

In addition to the drug-hypersensitive phenotypes, the $f k s l$ mutant exhibits a slow-growth phenotype, which is partially suppressed by $10 \mathrm{~mm}-\mathrm{Ca}^{2+}$. Other $\mathrm{Ca}^{2+}$-responsive mutants of yeast have also been described. A call mutant shows $\mathrm{Ca}^{2+}$-dependent growth at $23{ }^{\circ} \mathrm{C}$ with a sixfold longer doubling time in the absence of $\mathrm{Ca}^{2+}$ than in the presence of $100 \mathrm{~mm}-\mathrm{CaCl}_{2}$ (Ohya et al., 1984). It also fails to grow at $37^{\circ} \mathrm{C}$ on YPD unless supplemented with $\mathrm{CaCl}_{2}$ (Ohya et al., 1984). This mutant arrests in the cell division cycle with a tiny bud when transferred to $\mathrm{Ca}^{2+}$-poor media and incubated at the nonpermissive temperature. A $y p t t^{\text {ts }}$ mutant can be rescued from growth arrest at the nonpermissive temperature by 50-100 mM extracellular $\mathrm{Ca}^{2+}$ but grows normally on YPD at the permissive temperature (Schmitt et al., 1988). $Y P T 1$ encodes an essential ras-related guaninenucleotide-binding protein which localizes to the Golgi. The $f k s 1$ mutant differs from the call and ypt 1 strains both in the level of $\mathrm{Ca}^{2+}$ required for optimum growth and its lack of a $t s$ phenotype. Disruption of the $P M R I$ gene, encoding a P-type ATPase localized in a Golgi-like organelle, results in secretory and growth defects, which are worsened by EGTA and ameliorated by exogenously added $\mathrm{Ca}^{2+}$ (Rudolph et al., 1989; Antebi \& Fink, 1992).
However, unlike $f k s l$ strains, $p m r l$ strains appear to grow normally on YPD (Antebi \& Fink, 1992) and only grow poorly on synthetic minimal medium containing low concentrations of $\mathrm{Ca}^{2+}$. Although the $f k s 1$ mutation confers a phenotype which differs from those of the call, $y p t l$, and pmrl mutations, some of these differences could be due to allele-specific effects; its exact relationship to these other mutations, if any, awaits further work.

What is the nature of the $f k s 1$ mutation? One possibility is that the mutation increases permeability to the drugs. This is probably not the case. Recovery from mating factor arrest in wild-type $F K S 1$ cells is inhibited by concentrations of FK506 or CsA as low as those inhibiting the growth of the $f k s 1$ mutant. In addition, the mutant is unaltered in its sensitivity to several other antifungal drugs (Table 2) showing that the permeability to these drugs has not changed. It is therefore likely that the drugs enter both wild-type and mutant cells equally well and inhibit calcineurin and that the growth of the mutant is inhibited because the mutation has caused calcineurin to become essential.

The recessive character of the $f k s I$ mutation suggests that it may result in the loss of function of its gene product. The slow growth phenotype, $\mathrm{Ca}^{2+}$-responsiveness and calcineurin-dependence of the $f k s 1$ mutant imply that this loss of function may be partially replaced by calcineurin, which is activated by $\mathrm{Ca}^{2+}$. Yeast calcineurin is thought to be located exclusively in the cytoplasm (Cyert \& Thorner, 1992). The cytosolic level of $\mathrm{Ca}^{2+}$ in haploid cells increases from $70 \mathrm{nM}$, in cells exposed to $0.1 \mathrm{~mm}$ extracellular $\mathrm{Ca}^{2+}$, to $350 \mathrm{~nm}$ in cells suspended in media containing $10 \mathrm{~mm}-\mathrm{Ca}^{2+}$ (Halachmi \& Eilam, 1993). There is little further increase in cytosolic levels when the extracellular level of $\mathrm{Ca}^{2+}$ is increased above $10 \mathrm{~mm}$. We found that $10 \mathrm{~mm}$ extracellular $\mathrm{CaCl}_{2}$ was optimal for stimulating the growth of the $f k s l$ mutant; higher levels produced no further increase in growth rate. In vitro the $\mathrm{Ca}^{2+} /$ calmodulin-dependent actitivity of mammalian calcineurin is stimulated most significantly in the range $100-900 \mathrm{nM}-\mathrm{Ca}^{2+}$ (Stewart et al., 1982). These considerations suggest that the stimulation of the growth of the mutant by exogenously added $\mathrm{Ca}^{2+}$ is due to the activation of calcineurin, an idea supported by the observation that overexpression of the type 2 calcineurin stimulates growth. The magnitude of this effect is rather small compared to that caused by $\mathrm{Ca}^{2+}$, suggesting that $\mathrm{Ca}^{2+}$ may also exert its effect through a component other than calcineurin. It is possible that the $F K S I$ gene product is a protein phosphatase, with a specificity overlapped by that of calcineurin. However, the component compensating for the loss of the $F K S 1$ gene product may not be calcineurin but rather a component which is calcineurin-dependent. 
Thus, the FKSI gene product itself need not be a phosphatase.

The kinetics of inhibition of growth upon the addition of drug to an exponentially growing culture is consistent with the idea that the compensating component may be downstream of calcineurin. The binding of FK506 or CsA to their binding proteins and the inhibition of calcineurin phosphatase activity occurs rapidly in vitro (J. Nielsen, unpublished observations). If drug is quickly taken up by cells, one would expect that hyperphosphorylation of calcineurin substrates would occur soon thereafter. The inhibition of growth by the drugs, however, requires several hours, implying that the synthesis or accumulation of the growth-rate-limiting component may be inhibited by hyperphosphorylation of a calcineurin substrate, and that growth ceases only after dilution of this component by further growth after the addition of drug.

Growth of the hypersensitive mutant and recovery of wild-type cells from mating factor arrest are both calcineurin-dependent. We considered that FKSI might encode a function the loss of which leads to a state of constitutive pheromone recovery. However, such a condition should result in insensitivity to $\alpha$-factor, but the fks 1 mutant is as sensitive as the wild type. In addition, components of the mating pathway are generally under $a / \alpha$ control and not expressed in $a / \alpha$ diploids, yet a $/ \alpha f k s l / f k s 1$ diploids are slow-growing and fully drug-hypersensitive. The question also arises whether growth of the hypersensitive mutant and recovery from mating factor arrest also depend upon dephosphorylation of the same phosphoprotein by calcineurin. Our data do not directly address this issue. An increase in internal $\mathrm{Ca}^{2+}$ has been observed late in the response to mating factor (Iida et al., 1990). Deprivation of $\mathrm{Ca}^{2+}$ during this period results in a loss of viability. It is interesting to speculate that FK506 and CsA inhibit recovery from mating factor arrest by preventing calcineurin from transmitting this $\mathrm{Ca}^{2+}$ signal. If this is the case, growth of the hypersensitive mutant is different from the pheromone response, since these cells maintain viability during growth arrest caused by the drugs.

Mating factor arrest and recovery are transient phenomena. Under normal conditions, in the absence of cells of the opposite mating type, haploid cells eventually return to a non-calcineurin-dependent, drug-insensitive state. The hypersensitive mutant, however, is continuously calcineurin-dependent. The slow growth of the mutant may be due to a low basal activity of calcineurin in the absence of elevated levels of cytosolic $\mathrm{Ca}^{2+}$. Alternatively, transient increases in $\mathrm{Ca}^{2+}$ occurring at some point during the cell cycle may be sufficient to sustain growth. If this is the case, one might expect the fksl mutant to display a nonlinear progression through the cell cycle. Microscopic examination of this strain did not reveal any blatant alteration in the number of cells in various stages of the cell cycle, either when the cells were growing or when growth had ceased due to the presence of drug.

Like wild-type yeast cells, many mammalian cell types are refractory to FK506 and CsA action. An understanding of why wild-type yeast cells are relatively resistant to these drugs, while fksl cells are highly sensitive may provide insights into why some mammalian cells respond to these immunosuppressants while others do not. The $f k s 1$ mutant also provides a powerful genetic background for further studies of the mechanism of action of FK506 and CsA, as well as the role of calcineurin in vivo. Genetic selections for FK506- and/or CsA-resistant mutants in $f k s l$ strains should isolate interesting mutations in FKBP12, cyclophilin, calcineurin, and other gene products which lie in the $\mathrm{Ca}^{2+} /$ calcineurin-dependent signalling pathway.

The authors would like to thank G. Salituro for providing FK506, A. Marcy and $\mathrm{K}$. Chan for providing the E. coli FKBI expression plasmid, M. H. Pausch and J. Thorner for providing us their calmodulin purification procedure prior to publication, E. Harris and J. Thorner, J. Marrinan and C. Douglas for strains and plasmids, A. Shafiee for anti-FKBP12 antiserum, and N. Sigal, S. Ludmerer, M. Kurtz, J. Thompson, D. MacNeil and S. O'Keefe for helpful discussions and critical reading of the manuscript.

\section{References}

Antebi, A. \& Fink, G. R. (1992). The yeast $\mathrm{Ca}^{2+}$-ATPase homologue, $P M R l$, is required for normal golgi function and localizes in a novel golgi-like distribution. Molecular Biology of the Cell 3, 633-654.

BARTHELMESS, I. B. \& TROPSCHUG, M. (1993). FK506-binding protein of Neurospora crassa (NcFKBP) mediates sensitivity to the immunosuppressant FK506; resistant mutants identify two loci. Current Genetics 23, 54-58.

BECKER, D. M. \& GUARENTE, L. (1991). High-efficiency transformation of yeast by electroporation. Methods in Enzymology 194, 182-187.

Brizuela, L., Chrebet, G., Bostian, K. A. \& Parent, S. A. (1991). Antifungal properties of the immunosuppressant FK-506: identification of an FK-506-responsive yeast gene distinct from FKBI Molecular and Cellular Biology 11, 4616-4626.

Clipstone, N. A. \& Crabtree, G. R. (1992). Identification of calcineurin as a key signalling enzyme in T-lymphocyte activation. Nature, London 357, 695-697.

CYerT, M. S. \& ThORner, J. (1992). Regulatory subunit (CNBI gene product) of yeast $\mathrm{Ca}^{2+} /$ calmodulin-dependent phosphoprotein phosphatases is required for adaptation to pheromone. Molecular and Cellular Biology 12, 3460-3469.

Cyert, M. S., Kunisawa, R., Kaim, D. \& Thorner, J. (1991). Yeast has homologs (CNAI and CNA2 gene products) of mammalian calcineurin, a calmodulin-regulated phosphoprotein phosphatase. Proceedings of the National Academy of Sciences of the United States of America 88, 7376-7380.

DAVIS, T. N. \& THORNER, J. (1989). Vertebrate and yeast calmodulin, despite significant sequence divergence, are functionally interchangeable. Proceedings of the National Academy of Sciences of the United States of America 86, 7909-7913.

Foor, F., Parent, S. A., Morin, N., Dahl, A. M., Ramadan, N., Chrebet, G., Bostian, K. A. \& Nielsen, J. B. (1992). Calcineurin mediates inhibition by FK506 and cyclosporin of recovery from $\alpha$-factor arrest in yeast. Nature, London 360, 682-684. 
GiETz, R. D. \& Sugino, A. (1988). New yeast-Escherichia coli shuttle vectors constructed with in vitro mutagenized yeast genes lacking six-base pair restriction sites. Gene 74, 527-534.

Halachmi, D. \& Eilam, Y. (1993). Calcium homeostasis in yeast cells exposed to high concentrations of calcium: roles of vacuolar $\mathrm{H}^{+}$-ATPase and cellular ATP. FEBS Letters 316, 73-78.

Heitman, J., Movva, N. R., Hiestand, P. C. \& Hall, M. N. (1991). FK506-binding protein proline rotamase is a target for the immunosuppressive agent FK506 in Saccharomyces cerevisiae. Proceedings of the National Academy of Sciences of the United States of America 88, 1948-1952.

IIDA, H., YAGAWA, Y. \& ANRAKU, Y. (1990). Essential role for induced $\mathrm{Ca}^{2+}$ influx followed by $\left[\mathrm{Ca}^{2+}\right]_{i}$ rise in maintaining viability of yeast cells late in the mating pheromone response pathway: a study of $\left[\mathrm{Ca}^{2+}\right]_{i}$ in single Saccharomyces cerevisiae cells with imaging of fura-2. Journal of Biological Chemistry 265, 13391-13399.

Koltin, Y., Faucette, L., Bergsma, D. J., Levy, M. A., Cafferkey, R., Koser, P. L., Johnson, R. K. \& LiVI, G. P. (1991). Rapamycin sensitivity in Saccharomyces cerevisiae is mediated by a peptidylprolyl cis-trans isomerase related to human FK506-binding protein. Molecular and Cellular Biology 11, 1718-1723.

Koser, P. L., Bergsma, D. J., Cafferkey, R., Eng, W.-K., Mclaughlin, M. M., Ferrara, A., Silverman, C., Kasyan, K. Bossard, M. J., Johnson, R. K., Porter, T. G., Levy, M. A. \& Livi, G. P. (1991). The CYP2 gene of Saccharomyces cerevisiae encodes a cyclosporin A-sensitive peptidyl-prolyl cis-trans isomerase with an $\mathrm{N}$-terminal signal sequence. Gene 108, 73-80.

Kuno, T., Tanaka, H., Mukai, H., Chang, C.-D., Hiraga, K., MiYAKAWA, T. \& TANAKA, C. (1991). cDNA cloning of a calcineurin B homolog in Saccharomyces cerevisiae. Biochemical and Biophysical Research Communications 180, 1159-1163.

LiU, J., Farmer, J. D., JR, Lane, W. S., Friedman, J., Weissman, I. \& SCHREIBER, S. L. (1991 $a$ ). Calcineurin is a common target of cyclophilin-cyclosporin A and FKBP-FK506 complexes. Cell 66, 807-815.

Liu, Y., IshiI, S., Tokai, M., Tsutsumi, H., Ohki, O., AKada, R., Tanaka, K., Tsuchiya, E., Fukui, S. \& Miyakawa, T. (1991 $b$ ). The Saccharomyces cerevisiae genes (CMP1 and CMP2) encoding calmodulin-binding proteins homologous to the catalytic subunit of mammalian protein phosphatase 2B. Molecular and General Genetics 227, 52-59.

Mackay, V. L., Welch, S. K., Insley, M. Y., Manney, T. R., Holly, J., SAARI, G. C. \& PARKer, M. L. (1988). The Saccharomyces cerevisiae $B A R I$ gene encodes an exported protein with homology to pepsin. Proceedings of the National Academy of Sciences of the United States of America 85, 55-59.

Nakamura, T., Tsutsumi, H., Mukai, H., Kuno, T. \& Miyakawa, T.
(1992). $\mathrm{Ca}^{2+} /$ calmodulin-activated protein phosphatase (PP2B) of Saccharomyces cerevisiae: PP2B activity is not essential for growth. FEBS Letters 309, 103-106.

Niflsen, J. B., Hsu, M.-J., Byrne, K. M. \& Kaplan, L. (1991). Biosynthesis of the immunosuppressant immunomycin: the enzymology of pipecolate incorporation. Biochemistry 30, 5789-5796.

Nielsen, J. B., Foor, F., Siekierka, J. J., Hsu, M.-J., Ramadan, N., Morin, N., Shafiee, A., Dahl, A. M., Brizuela, L., Chrebet, G., Bostian, K. A. \& Parent, S. A. (1992). Yeast FKBP-13 is a membrane-associated FK506-binding protein encoded by the nonessential gene FKB2. Proceedings of the National Academy of Sciences of the United States of America 89, 7471-7475.

OHYA, Y., OHSUMI, Y. \& ANRAKU, Y. (1984). Genetic study of the role of calcium ions in the cell division cycle of $S$. cerevisiae: a calciumdependent mutant and its trifluoperazine-dependent pseudorevertants. Molecular and General Genetics 193, 389-394.

O'Keefe, S. J., Tamura, J., Kincaid, R. L., Tocci, M. J. \& O'Neill, E. A. (1992). FK-506- and CsA-sensitive activation of the interleukin-2 promoter by calcineurin. Nature, London 357, 692-694.

Pallen, C. J., Sharma, R. K. \& Wang, J. H. (1988). Regulation of calcineurin: a multifunctional calmodulin-stimulated phosphatase. In Calcium-Binding Proteins, pp. 51-82. Edited by M. P. Thompson. Boca Raton, FL: CRC Press.

Rudolph, H. K., Antebi, A., Fink, G. R., Buckley, C. M., Dorman, T. E., LeVitre, J., Davidow, L. S., MAO, J. \& Moir, D. T. (1989). The yeast secretory pathway is perturbed by mutations in $P M R 1$, a member of $\mathrm{a} \mathrm{Ca}^{2+}$ ATPase family. Cell 58, 133-145.

Schmitt, H. D., Puzicha, M. \& Gallwitz, D. (1988). Study of a temperature-sensitive mutant of the ras-related $Y P T I$ gene product in yeast suggests a role in the regulation of intracellular calcium. Cell $53,635-647$.

SCHREIBER, S. L. (1992). Immunophilin-sensitive protein phosphatase action in cell signaling pathways. Cell 70, 365-368.

Sherman, F., Fink, G. R. \& Hicks, J. B. (1986). Methods in Yeast Genetics. Cold Spring Harbor, NY: Cold Spring Harbor Laboratory.

Sigal, N. H. \& Dumont, F. J. (1992). Cyclosporin A, FK-506, and rapamycin: pharmacologic probes of lymphocyte signal transduction. Annual Reviews of Immunology 10, 519-560.

Stewart, A. A., Ingebritsen, T. S., Manalan, A., Klee, C. B. \& CoHen, P. (1982). Discovery of a $\mathrm{Ca}^{2+}-$ and calmodulin-dependent protein phosphatase. FEBS Letters $137,80-84$.

TropsChug, M., Barthelmess, I. B. \& NeUPERT, W. (1989). Sensitivity to cyclosporin A is mediated by cyclophilin in Neurospora crassa and Saccharomyces cerevisiae. Nature, London 346, 953-955.

Wiederrecht, G., Hung, S., Chan, H. K., Marcy, A., Martin, M., Calaycay, J., Boulton, D., Sigal, N., Kincaid, R. L. \& Siekierka, J. J. (1992). Characterization of high molecular weight FK-506 binding activities reveals a novel FK-506-binding protein as well as a protein complex. Journal of Biological Chemistry 267, 21753-21760. 